\title{
Avaliação sazonal de índices de estado trófico para fósforo total para mananciais de abastecimento público do Município de Goiânia, Estado do Goiás, Brasil
}

\section{Adrielle Alcântara Santos ${ }^{1}, *$, Debora Pereira da Silva ${ }^{1}$, Isabella Almeida Costa ${ }^{1}$ e Renata Medici Frayne Cuba ${ }^{2}$}

${ }^{1}$ Universidade Federal de Goiás. Programa de Pós-Graduação em Engenharia Ambiental e Sanitária. Escola de Engenharia Civil e Ambiental. Av.Universitária, 1488, Q. 86, L. Área Setor Universitário. Goiânia-GO, Brasil (CEP 74605-220). *E-mail: adrielle.as@hotmail.com.

${ }^{2}$ Universidade Federal de Goiás. Escola de Engenharia Civil e Ambiental. Av. Universitária, 1488. Setor Universitário. Goiânia-GO, Brasil (CEP 74605-220).

Resumo. O nível de eutrofização de um curso d'água pode ser medido pelo Índice de estado trófico (IET). O objetivo desta pesquisa foi analisar a variação sazonal da qualidade da água através da determinação do IET dos mananciais de abastecimento do Município de Goiânia, Estado de Goiás, Brasil. As amostras foram coletadas, nos pontos de captação de duas estações de tratamento de água e o IET foi determinado segundo as equações propostas na literatura para ambiente lótico. Analisaram-se as variáveis físicas, químicas e biológicas. As variáveis fósforo total, cor aparente, DBO, sólidos dissolvidos totais e E. coli não estão em conformidade com a Resolução do Conselho Nacional de Meio Ambiente (CONAMA). Conclui-se que há correlação entre as estações do ano e o nível de eutrofização $(p=0,016)$. Valores mais críticos ocorreram para o período seco, no qual se verificou a classe mesotrófica no ponto P1 e P2; e no período chuvoso a classe foi ultraoligotrófica em P2.

Palavras-chave: Abastecimento de água; Eutrofização; Índice de Estado Trófico; Qualidade da água.

Abstract. Seasonal evaluation of trophic state indices for total phosphorus for public water sources in Municipality of Goiânia, Goiás State, Brazil. The eutrophication level of a watercourse can be measured by the Trophic State Index (TRIX). The aim of this research was to analyze the seasonal variation of water quality through the determination of TRIX from supply sources of Goiânia Municipality, Goiás State, Brasil. The samples were collected at catchment points of two water treatment plants and the TRIX was determined according to equations proposed in the literature for lotic environments. Physical, chemical and
Recebido:

03/09/2019

Aceito:

26/12/2019

Publicado:

31/12/2019

Acesso aberto

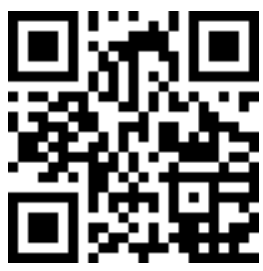

ORCID

(D) 0000-0003-2976-4066 Adrielle Alcântara Santos

D 0000-0001-9703-3156 Debora Pereira da Silva

(D) 0000-0002-6818-7604 Isabella Almeida Costa 
biological parameters were analyzed. Total phosphorus, apparent color, BOD, TDS and E. coli variables are not in compliance with Brazilian National Environment Council (CONAMA) resolution. It was concluded that there is correlation between the seasons and levels of eutrophication $(p=0.016)$, more critical values occurred for dry period, showing mesotrophic class at points P1 and P2; and ultraoligotrophic class for rainy season at P2.

Keywords: Water supply; Eutrophication; Trophic index; Water quality.

\section{Introdução}

Conforme Andretti et al. (2016), os diferentes e crescentes usos da água comprometem a qualidade de cursos hídricos solicitados por essa demanda. É de interesse principalmente das grandes capitais brasileiras, cujas solicitações de abastecimento são maiores, que haja transparência nas políticas públicas de saneamento. Sendo assim, foi escolhida a metrópole de Goiânia para a realização de um estudo de monitoramento.

O Sistema de Abastecimento de Água (SAA) do Município de Goiânia é constituído da Estação de Tratamento de Água (ETA) Jaime Câmara que capta água do Ribeirão João Leite e abastece $52 \%$ da população e a ETA Engenheiro Rodolfo José da Costa e Silva que atende $48 \%$ através do tratamento da água do Rio Meia Ponte (Vasconcelos et al., 2002). Deste modo, Cunha e Borges (2015) explicam que a Região Metropolitana de Goiânia é quase que exclusivamente dependente do "terço superior da Bacia Hidrográfica do Rio Meia Ponte e da metade inferior da Bacia do Ribeirão João Leite".

O Ribeirão João Leite tem sido motivo de preocupação pelas contribuições industriais, agropecuárias, e de resíduos sólidos ao longo do seu curso (Cunha e Borges, 2015); enquanto o Rio Meia Ponte já lida com um diagnóstico que caracteriza seu trecho da nascente até a cidade de Pontalina como efluente típico de esgoto doméstico (Mendes et al., 2016).

Um grande agente responsável pelo comprometimento da água de mananciais é a eutrofização. Sinha et al. (2017) definem eutrofização como um processo de enriquecimento de nutrientes como nitrogênio e fósforo em um corpo d'água que sofre diferentes contribuições ao longo do tempo. Para que haja objetividade e resultados confiáveis, esse nível de eutrofização pode ser medido através de um índice de estado trófico (IET) em diferentes estações do ano.

Por ter também aplicação globalizada, o cálculo do IET é constantemente criado e reformulado em várias partes do mundo. Para um melhor entendimento, Farage et al. (2010) consideram-no: i) um conceito multidimensional que abrange transporte e concentração de nutrientes; e produtividade, quantidade e qualidade da biota e ii) uma análise multiparamétrica, que acaba por dificultar a definição das variáveis a serem utilizadas.

A escolha do índice ideal deve ser feita considerando as seguintes abordagens: i) volume e tipo de informação disponível, ii) logística e custos de obtenção dos dados e iii) tempo empregado durante o processo de coleta desses dados (López-Monroy e Troccoli-Ghinaglia, 2018). Então, com o índice escolhido, os interessados poderão obter um diagnóstico apresentado por níveis de trofia, uma vez que parâmetros de qualidade da água soltos, e sem as devidas associações, não são tão bem compreendidos pela sociedade.

Os índices escolhidos foram os de Carlson (1977), que apresenta facilidade de aplicação e obtenção de variáveis de entrada, o índice de Carlson adaptado para ambientes tropicais de Toledo Jr. (1983; 1984), e o índice de Lamparelli (2004), para ambientes lóticos e lênticos. 
O Rio Meia Ponte e o Ribeirão João Leite são destinados a usos múltiplos, como para o abastecimento em Goiânia em sua totalidade, Aparecida de Goiânia e Trindade, além de irrigação. Desta forma, é de extrema importância que se determine o nível de estado trófico dos mananciais, visando a aumentar a segurança para o uso dessa água, que é determinante na saúde pública, e fornecer subsídio à gestão das bacias hidrográficas.

Neste contexto, esta pesquisa teve como objetivo analisar a variação sazonal do nível de estado trófico dos mananciais de abastecimento do município de Goiânia, por meio da determinação do índice de estado trófico (IET) para fósforo total.

\section{Metodologia}

\section{Áreas de estudo}

As regiões de estudo compreendem as Bacias Hidrográficas do Ribeirão João Leite e do Rio Meia Ponte, especifica- mente nos pontos de captação da ETA Engenheiro Rodolfo José da Costa e Silva (P1) e ETA Jaime Câmara (P2) que abastecem a população goiana.

Com relação à Bacia Hidrográfica do Ribeirão João Leite, a área de drenagem é de $766,80 \mathrm{~km}^{2}$, possui como vegetação predominante o cerrado e o curso d'água possui uma extensão de $85 \mathrm{~km}$, sendo que sua nascente localiza-se nas proximidades do Município de Ouro Verde de Goiás e a sua foz no Rio Meia Ponte (Santos et al., 2010).

A Bacia Hidrográfica do Rio Meia Ponte abrange uma área de drenagem de $11.550 \mathrm{~km}^{2}$, o rio nasce no Município de Itauçu e estende-se por $550 \mathrm{~km}$ até o ponto de deságue no Rio Paranaíba (Monteiro et al., 2008). Sendo delimitados dois pontos amostrais pertencentes aos mananciais superficiais de captação do Município de Goiânia (Figura 1).

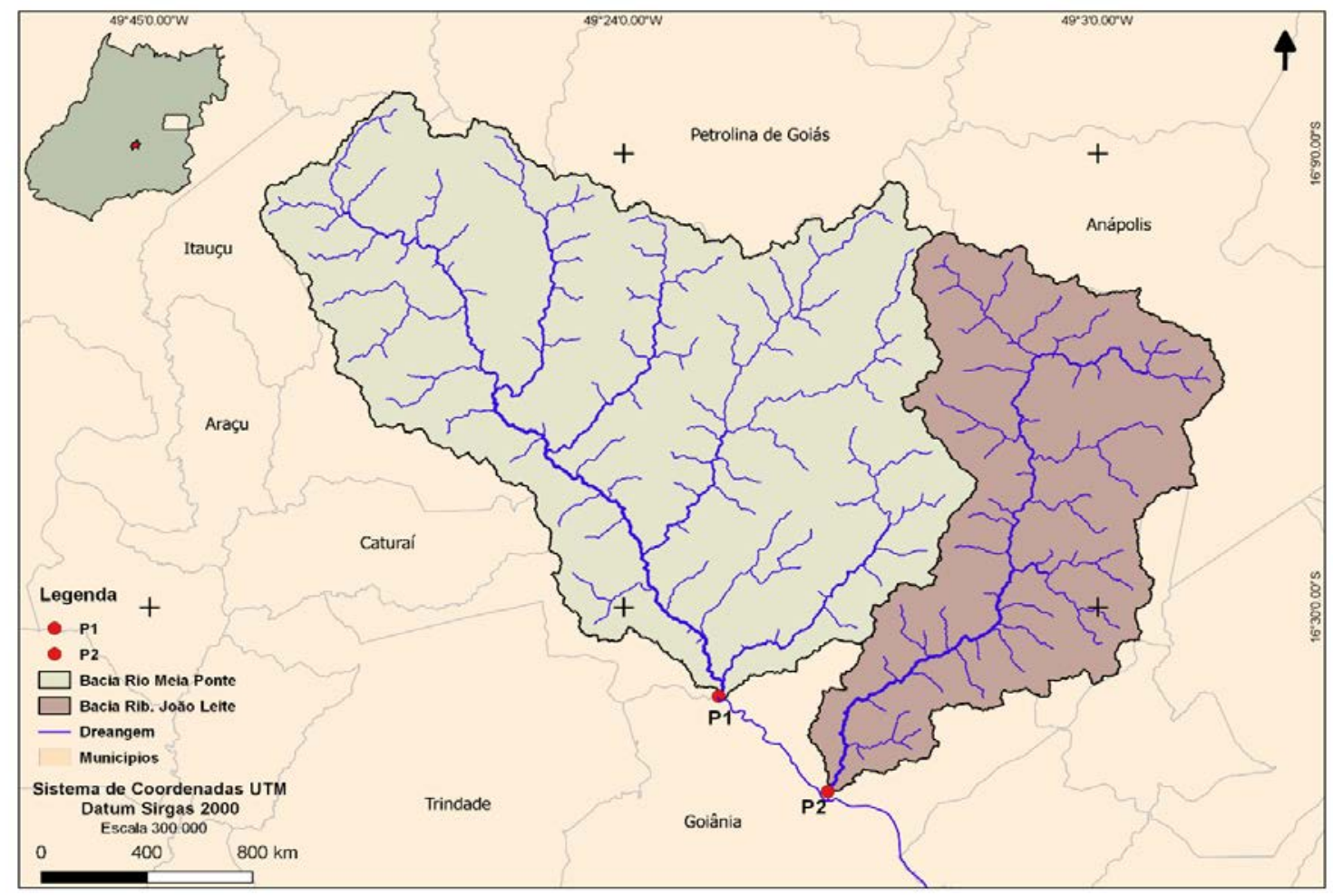

Figura 1. Localização das bacias hidrográficas do rio Meia Ponte e Ribeirão João Leite e distribuição dos pontos amostrais P1 e P2. Os pontos P1 e P2 pertencem aos pontos de captação das ETAs no rio Meia Ponte e ribeirão João Leite, respectivamente. 


\section{Clima e estações pluviométricas}

Em função da classificação de Köppen (1948), a Região de Goiânia apresenta um clima Tropical úmido (Aw), no qual a estação seca ocorre de maio a setembro e a estação chuvosa entre os meses de outubro e abril.

Os dados pluviométricos do período analisado foram obtidos na estação Evaporimétrica de Goiânia da Escola de Agronomia da UFG situada nas proximidades do ponto P1 e na estação convencional $\mathrm{n}$ o 83423 do Instituto Nacional de Meteorologia (INMET, 2019) localizada nas proximidades do ponto P2.

Campanha de amostragem e procedimentos laboratoriais

A campanha de amostragem de água bruta compreende quatro coletas no período seco (junho a setembro de 2018) e três no período chuvoso (outubro a dezembro de 2018). As amostras de água foram coletadas, preservadas e transportadas conforme indicação do guia da CETESB (2011).

A variável clorofila- $a$ foi determinada conforme método espectrofotométrico (CETESB, 2011). Analisou-se também as variáveis temperatura da água $\left(\mathrm{T}_{\mathrm{H} 2 \mathrm{O}}\right)$, $\mathrm{pH}$, cor aparente (CA), oxigênio dissolvido (OD), turbidez (TB), condutividade elétrica (CE), alcalinidade $(\mathrm{A})$, cloreto $(\mathrm{Cl})$, dureza (D), sólidos dissolvidos totais (SDT), nitrato $\left(\mathrm{NO}_{3}\right)$, fósforo total (PT), demanda bioquímica de oxigênio (DBO), coliformes totais (CT) e Escherichia coli (EC) pelo Standard Methods (APHA, 2012).

A partir dos dados amostrais, relacionaram-se as concentrações das variáveis com os limites estabelecidos na Resolução CONAMA no 357/2005 (Brasil, 2005), em decorrência da destinação ao abastecimento para consumo humano.

\section{Índices de estado trófico (IET)}

A partir da concentração de fósforo total analisou-se o enriquecimento por nutrientes dos mananciais através da determinação do IET proposto por Toledo Jr. et al. (1983; 1984) e o IET desenvolvido por Lamparelli (2004) para ambientes lóticos.

Desta forma, considerou-se para o cálculo do IET $_{1}$ apenas a variável fósforo total, utilizando a Equação 1 de Toledo Jr. et al. (1983; 1984), em decorrência dos resultados inconsistentes de clorofila- $a$, devido a alta correnteza, turbidez e presença de sólidos suspensos, que, segundo Farage et al. (2010), são características comuns aos mananciais que abastecem o Município de Goiânia.

0 Índice de Lamparelli (2004) foi desenvolvido com a finalidade de ajustar o método de monitoramento do grau de eutrofização para as características inerentes aos ambientes lóticos e lênticos de forma separada. Logo, utilizou-se a Equação 2 no cálculo do $\mathrm{IET}_{2}$ para regimes lóticos considerando somente a variável fósforo total.

$$
\begin{aligned}
& \operatorname{IET}(P T)=10 *\left(6-\frac{\left(\frac{\ln \ln 80,32}{P T}\right)}{\ln \ln 2}\right) \\
& \operatorname{IET}(P T)=10 *\left(6-\frac{(0,42-(0,36 * \ln \ln P T))}{\ln \ln 2}\right)-20
\end{aligned}
$$

Em que: $\mathrm{PT}$ = concentração de fósforo total medida à superfície da água, em $\mu \mathrm{g} / \mathrm{L}$; $\ln =$ logaritmo natural. 
Para a classificação dos níveis tróficos em função da concentração de fósforo total e dos valores de IET, utilizou- se a Tabela 1 proposta por Toledo Jr. (1990) e a Tabela 2 modificada por Lamparelli (2004).

Tabela 1. Classificação do nível de estado trófico, segundo o sistema proposto por Toledo Jr. (1990).

\begin{tabular}{lcc}
\hline Nível trófico & PT $(\boldsymbol{\mu g} / \mathbf{L})$ & IET $_{\mathbf{1}}$ \\
\hline Ultraoligotrófico & $\mathrm{PT} \leq 6$ & IET $\leq 24$ \\
Oligotrófico & $7<\mathrm{PT} \leq 26$ & $24<$ IET $\leq 44$ \\
Mesotrófico & $27<\mathrm{PT} \leq 52$ & $44<$ IET $\leq 54$ \\
Eutrófico & $53<\mathrm{PT} \leq 211$ & $54<\mathrm{IET} \leq 74$ \\
Hipereutrófico & $\mathrm{PT}>211$ & IET $>74$ \\
\hline
\end{tabular}

Tabela 2. Classificação do nível de estado trófico, segundo o sistema proposto por Lamparelli (2004).

\begin{tabular}{lcc}
\hline Nível trófico & PT $(\boldsymbol{\mu g} / \mathbf{L})$ & IET $_{\mathbf{2}}$ \\
\hline Ultraoligotrófico & $\mathrm{PT} \leq 13$ & IET $\leq 47$ \\
Oligotrófico & $13<\mathrm{PT} \leq 35$ & $47<$ IET $\leq 52$ \\
Mesotrófico & $35<\mathrm{PT} \leq 137$ & $52<$ IET $\leq 59$ \\
Eutrófico & $137<\mathrm{PT} \leq 296$ & $59<\mathrm{IET} \leq 63$ \\
Supereutrófico & $296<\mathrm{PT} \leq 640$ & $63<$ IET $\leq 67$ \\
Hipereutrófico & $\mathrm{PT}>640$ & IET $>67$ \\
\hline
\end{tabular}

\section{Análise estatística}

Os parâmetros físicos, químicos e biológicos foram analisados pelo método de análise estatística descritiva, por meio da determinação da média, do desvio padrão $(\sigma)$ e do coeficiente de variação (CV). Os valores de IET foram analisados considerando dois fatores: os pontos amostrais (P1 e P2) e as estações do ano (seca e chuvosa) utilizando o teste exato de Fisher. 0 nível de significância utilizado foi de $p<0,05(95 \%)$.

\section{Resultados e discussão mensal}

Os dados pluviométricos registrados entre o período de junho/2018 a dezembro/2018 nas estações pluviométricas são apresentados na Figura 2.

Verifica-se no Ponto Amostral P1 que o mês de novembro/2018 apresentou o maior valor de precipitação total mensal (248 mm). No entanto, esse resultado está divergente ao verificado por Lobato (2005) ao analisar a série histórica do Ponto Amostral P1 entre o período de 1975 e 2004, no qual constatou que o mês com maior precipitação pluviométrica corresponde ao mês de dezembro. Verifica-se também que os meses de agosto, setembro e novembro do ano de 2018 apresentaram valores de chuva 
mensal superior as normais climatológicas obtidas por Lobato (2005).

No Ponto Amostral P2 observa-se que o mês de outubro apresentou o maior valor de precipitação total mensal (224 $\mathrm{mm}$ ), representando assim um aumento de 58,8\% com relação à chuva medida no Ponto Amostral P1 para o mês analisado.

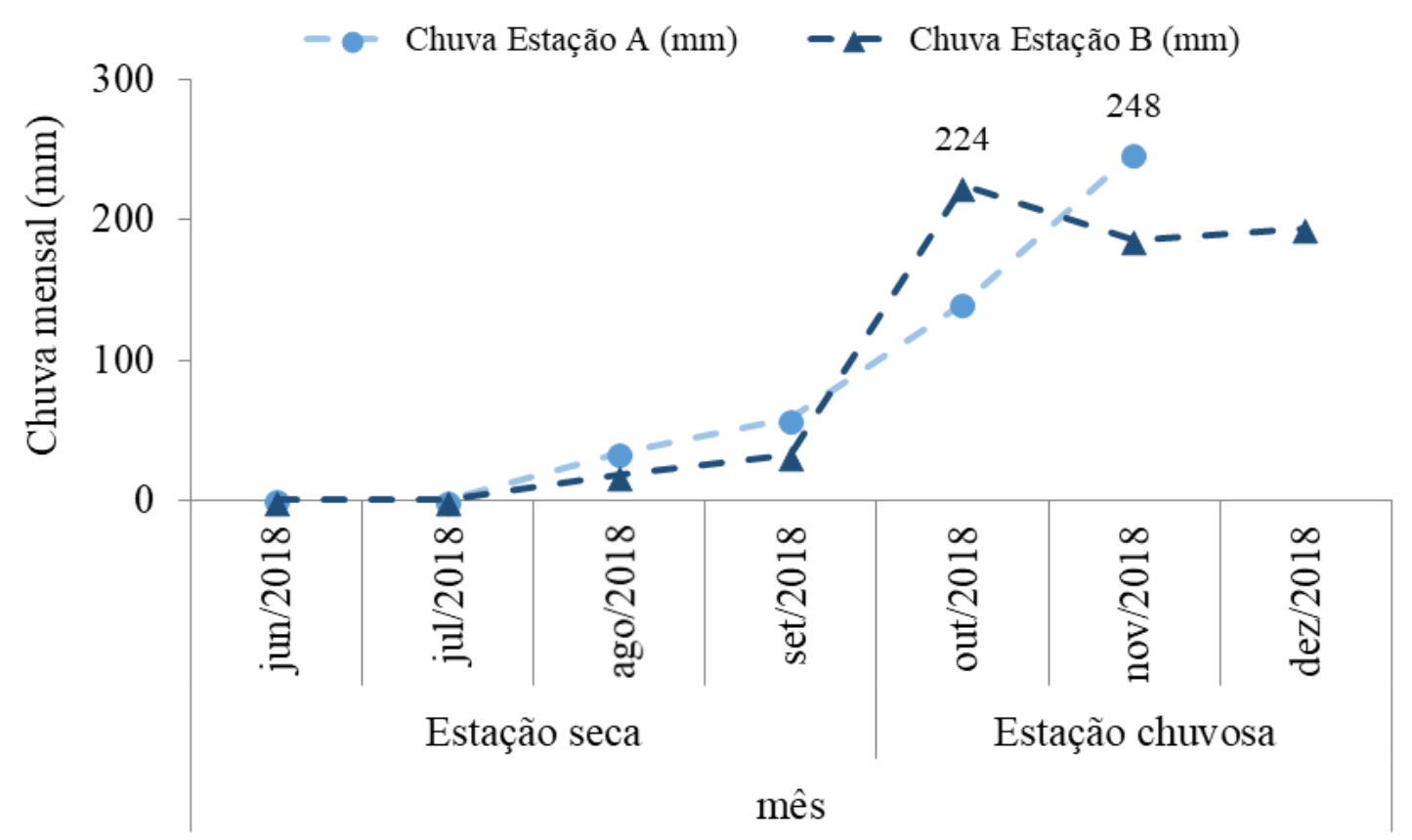

Figura 2. Dados de precipitação mensal (mm) para os meses da estação seca (junho a setembro) e estação chuvosa (outubro a dezembro) da Estação Evaporimétrica de Goiânia da Escola de Agronomia da UFG (Ponto Amostral P1) e da Estação Convencional no 83423 do INMET (no Ponto Amostral 2).

\section{Índices de estado trófico (IET)}

Na Tabela 3 estão apresentadas as concentrações de fósforo total, os valores de IET $_{1}$ e IET IET $_{2}$ e suas respectivas classificações, conforme demonstrados na Tabela 1 e na Tabela 2. Para a determinação do grau de eutrofização dos mananciais considerou-se apenas a concentração de fósforo total, semelhante à pesquisa realizada por Farage et al. (2010) e Silva et al. (2010).

Com a finalidade de verificar qual o índice adequado, com maior coerência e sensibilidade, para avaliação periódica do grau de eutrofização dos mananciais de abastecimento de Goiânia, comparou-se as classificações obtidas por intermédio da concentração de fósforo total com as classes de nível trófico do $\operatorname{IET}_{1}$, o qual se verificou no período seco do ponto P1 que $75 \%$ das coletas apresentaram classificações coerentes e no período chuvoso, 33,33\%. No período seco observou-se no ponto P2 que $50 \%$ dos resultados de nível trófico foram coerentes, enquanto que, no período chuvoso todas as classificações foram divergentes. Logo, pode se aferir que as classificações do valor de IET $_{1}$, em 87,5\% das amostras foi superior à obtida pelo fósforo total.

Ao comparar as classificações das mesmas concentrações de fósforo total obtidas nas campanhas de amostragem com os valores de $\mathrm{IET}_{2}$ utilizando o sistema de classe proposto por Lamparelli 
(2004), verifica-se no período chuvoso e seco do ponto P1 e P2 que $100 \%$ dos resultados de classe foram coerentes, logo constatou-se que o $\mathrm{IET}_{2}$ apresentou maior sensibilidade para a variação da concentração do fósforo total em decorrência das características sazonais. Este resultado demonstra que Lamparelli (2004) foi assertivo ao desenvolver índices levando em consideração as distinções entre os ambientes lóticos e lênticos.

Para relatar qual o índice mais conservador com relação à classificação do nível trófico, comparou-se as classes de trofia, constatando que as classificações do $\mathrm{IET}_{1}$ foram superiores ao $\mathrm{IET}_{2}$ em $85,7 \%$ das amostras analisadas nos pontos P1 e $\mathrm{P} 2$, logo pode-se constatar que o $\mathrm{IET}_{1}$ apresentou níveis maiores de eutrofização, podendo levar a classificações superestimadas. Esse fenômeno também foi constatado por Fia et al. (2009) na Bacia Hidrográfica da Lagoa Mirim, no Rio Grande do Sul, para regimes lóticos.

Considerando que o IET $_{2}$ obteve resultados com alta confiabilidade quanto ao nível de estado trófico, verifica-se em P1 para o período seco três classes de trofia, com destaque para a classificação mesotrófica em $50 \%$ das amostras, e no período chuvoso observa-se três classes de trofia (ultraoligotrófica, oligotrófica e mesotrófica) com a mesma representatividade de $33,33 \%$.

Observa-se no ponto P2 para o período seco dois níveis de trofia, destacando-se a classificação mesotrófica em $75 \%$ das coletas, e no período chuvoso dois níveis de trofia, com destaque para a classificação ultraoligotrófica em $66,67 \%$.

Tabela 3. Classificação do nível de estado trófico nos pontos amostrais P1 e P2 baseado na concentração de fósforo total, no valor IET 1 proposto por Toledo et al. (1983) para ambientes tropicais e no valor de IET $_{2}$ desenvolvido por Lamparelli (2004).

\begin{tabular}{|c|c|c|c|c|c|c|c|c|c|}
\hline \multirow{2}{*}{ Estação } & \multirow{2}{*}{ Data } & PT $(\mu \mathrm{g} / \mathrm{L})$ & IET $_{1}$ & PT $(\mu \mathrm{g} / \mathrm{L})$ & IET $_{2}$ & PT $(\mu \mathrm{g} / \mathrm{L})$ & IET $_{1}$ & PT $(\mu \mathrm{g} / \mathrm{L})$ & IET $_{2}$ \\
\hline & & \multicolumn{4}{|c|}{ P1 } & \multicolumn{4}{|c|}{ P2 } \\
\hline \multirow{8}{*}{ Seca } & \multirow{2}{*}{$\begin{array}{l}\text { jun/ } \\
2018\end{array}$} & 87,02 & 59,27 & 87,02 & 57,14 & 73,88 & 59,14 & 73,88 & 56,29 \\
\hline & & E & $\mathrm{E}$ & M & M & $\mathrm{E}$ & E & M & M \\
\hline & \multirow{2}{*}{$\begin{array}{c}\text { jul/ } \\
2018 \\
\end{array}$} & 16,16 & 56,08 & 16,16 & 48,39 & 43,59 & 58,55 & 43,59 & 53,55 \\
\hline & & 0 & $\mathrm{E}$ & 0 & 0 & $\mathrm{M}$ & E & $\mathrm{M}$ & M \\
\hline & \multirow{2}{*}{$\begin{array}{l}\text { ago/ } \\
2018 \\
\end{array}$} & 194,46 & 59,67 & 194,46 & 61,31 & 302,46 & 59,79 & 302,46 & 63,61 \\
\hline & & $\mathrm{E}$ & $\mathrm{E}$ & '1E1 & $\mathrm{E}$ & $\mathrm{H}$ & $\mathrm{E}$ & $\mathrm{S}$ & $\mathrm{S}$ \\
\hline & \multirow{2}{*}{$\begin{array}{c}\text { set/ } \\
2018\end{array}$} & $Q$ & 58,96 & 60,73 & 55,27 & 71,02 & 59,11 & 71,02 & 56,08 \\
\hline & & $\mathrm{E}$ & $\mathrm{E}$ & $\mathrm{M}$ & M & $\mathrm{E}$ & E & M & M \\
\hline \multirow{6}{*}{ Chuvosa } & \multirow{2}{*}{$\begin{array}{c}\text { out/ } \\
2018\end{array}$} & 4,16 & 44,79 & 4,16 & 41,34 & 5,87 & 49,23 & 5,87 & 43,14 \\
\hline & & $\mathrm{U}$ & $\mathrm{M}$ & $\mathrm{U}$ & $\mathrm{U}$ & $\mathrm{U}$ & $\mathrm{M}$ & $\mathrm{U}$ & $\mathrm{U}$ \\
\hline & \multirow{2}{*}{$\begin{array}{l}\text { nov/ } \\
2018 \\
\end{array}$} & 82,16 & 59,23 & 82,16 & 56,84 & 17,02 & 56,28 & 17,02 & 48,66 \\
\hline & & E & E & $\mathrm{M}$ & $\mathrm{M}$ & 0 & E & 0 & 0 \\
\hline & \multirow{2}{*}{$\begin{array}{c}\text { dez/ } \\
2018\end{array}$} & 25,45 & 57,51 & 25,45 & 50,75 & 2,44 & 34,12 & 2,44 & 38,58 \\
\hline & & 0 & E & 0 & 0 & $\mathrm{U}$ & 0 & $\mathrm{U}$ & U \\
\hline
\end{tabular}

U - Ultraoligotrófico; 0 - Oligotrófico; M - Mesotrófico; E - Eutrófico; S - Supereutrófico; H Hipereutrófico; Sublinhado - concentração acima do limite estabelecido pela Resolução CONAMA n⿳o 357/2005 (Brasil, 2005).

Na Tabela 4, estão apresentados os resultados do teste de Fisher. Verifica-se que os valores de IET apresentaram diferença significativa em relação às estações do ano $(p=0,016)$, porém em relação aos pontos amostrais não houve diferença significativa $(\mathrm{p}=1,538)$. 
Sendo assim, devido à associação entre o grau de eutrofização e as estações do ano, verifica-se no ponto P1 e P2 uma redução da concentração de fósforo total e dos valores de IET no período chuvoso, logo pode-se constatar que no período com elevadas precipitações a qualidade da água não é caracterizada como deteriorada para o abastecimento público. Já no período seco, verifica-se valores maiores de níveis tróficos, que podem comprometer a qualidade da água para usos múltiplos.

0 aumento do nível trófico no período seco também foi constatado por Alves et al. (2011) no Rio Arari localizado no norte do Brasil, em decorrência da elevada concentração de fósforo e biomassa fitoplanctônica, no qual classificou a estação seca como hipereutrófica e a chuvosa como supereutrófica.

Com relação aos pontos amostrais, verifica-se que apresentaram valores de nível de estado trófico aproximados, ainda que pertencentes a bacias hidrográficas distintas.

Tabela 4. Resultados de Fisher para a variável IET desenvolvida por Lamparelli (2004), considerando os pontos amostrais (P1 e P2) e a estação do ano (seca e chuvosa).

\begin{tabular}{|c|c|c|c|c|c|c|c|}
\hline \multirow{2}{*}{ Variáveis } & \multicolumn{2}{|c|}{ IET $\leq 52$} & \multicolumn{2}{|c|}{ IET > 52} & \multicolumn{2}{|c|}{ Total } & \multirow{2}{*}{$\mathbf{p}$} \\
\hline & $\mathbf{n}$ & $\%$ & $\mathbf{n}$ & $\%$ & $\mathbf{n}$ & $\%$ & \\
\hline \multicolumn{8}{|c|}{ Estação do ano $(n=14)$} \\
\hline Seca & 1 & $17 \%$ & 7 & $88 \%$ & 8 & $57 \%$ & \multirow{2}{*}{$0,016^{*}$} \\
\hline Chuvosa & 5 & $83 \%$ & 1 & $13 \%$ & 6 & $43 \%$ & \\
\hline \multicolumn{8}{|c|}{ Pontos amostrais $(n=14)$} \\
\hline P1 & 3 & $50 \%$ & 4 & $50 \%$ & 7 & $50 \%$ & \multirow{2}{*}{2,387} \\
\hline $\mathrm{P} 2$ & 3 & $50 \%$ & 4 & $50 \%$ & 7 & $50 \%$ & \\
\hline
\end{tabular}

${ }^{*} \mathrm{p}<0,05$ - Houve diferença significativa entre as variáveis.

\section{Análise das variáveis de qualidade de água \\ De acordo com os resultados das} análises laboratoriais (Tabela 5), algumas variáveis apresentaram valores acima do estabelecido pela Resolução CONAMA no $357 / 2005$ (Brasil, 2005), para corpos de água doce do tipo Classe 2 .

Com relação aos limites estabelecidos nesta resolução, observa-se que o limite máximo do parâmetro PT corresponde a $0,1 \mathrm{mg} / \mathrm{L}(100 \mu \mathrm{g} / \mathrm{L})$ para ambientes lóticos. As amostras de agosto nos pontos P1 $(0,1946 \mathrm{mg} / \mathrm{L})$ e P2 $(0,30246 \mathrm{mg} / \mathrm{L})$ apresentaram valores superiores ao limite (Tabela 3). Consequentemente, essas amostras foram classificadas com os maiores graus de eutrofização identificados no período seco dos pontos amostrais P1 e P2, que correspondem a eutrófico e supereutrófico, respectivamente. Também foi detectado odor desagradável em P2 durante a realização da campanha de coleta em agosto, o que se considera mais um indicativo de água contaminada. 
$\mathrm{A} \mathrm{T}_{\mathrm{H} 20}$ apresentou média de $20,8^{\circ} \mathrm{C}$ e $22,5^{\circ} \mathrm{C}$ no período de estiagem e de 25,5 e $25,2{ }^{\circ} \mathrm{C}$ no período chuvoso nos pontos P1 e P2, respectivamente, sendo assim, verifica-se que o $\mathrm{CV}$ variou de $1,6 \%$ a $7,2 \%$, apresentando baixa dispersão ( $\mathrm{CV} \leq$ $15 \%$ ) dos dados, característico do clima Tropical úmido (Aw).

A Resolução CONAMA no 357/2005 (Brasil, 2005) estabelece um intervalo de $\mathrm{pH}$ entre 6,0 a 9,0, desta forma verifica-se que no ponto P1 a variação da média do $\mathrm{pH}$ ficou entre $7,4 \mathrm{e}$ 7,5 e o CV entre $0,7 \%$ e $2,7 \%$, e no ponto P2 a média dos valores de $\mathrm{pH}$ foi de 7,5 em qualquer estação do ano e o CV variou de $1,3 \%$ a $2,2 \%$, logo houve baixa variabilidade (CV $\leq 15 \%$ ) dos valores de $\mathrm{pH}$ estando próximo da neutralidade nos dois mananciais de abastecimento (Tabela 5).

A variável CA consiste na coloração devido à matéria em suspensão e dissolvida (Libânio, 2010), na qual pode ser resultante de possíveis fontes de contaminação antrópica como lançamentos industriais e domésticos e devido à origem natural como decomposição de matéria orgânica oriunda de pântanos e florestas (IMASUL, 2018).

Verifica-se no ponto P1 que $66,67 \%$ das coletas no período chuvoso não estão em conformidade com a resolução para a variável CA e que o CV nesse período foi de 48,3\%, logo houve alta dispersão dos dados (CV > 30\%), o que pode indicar alterações nas características do curso d'água em decorrência de partículas carreadas pelos eventos chuvosos antecedentes às datas da coleta.

A variável TB apresenta origem antrópica e natural, podendo apresentar altas concentrações associadas ao lançamento de efluentes (Libânio, 2010). Verifica-se que a média na estação seca foi de 8,9 NTU e 10 NTU e na chuvosa foi de 29,1 NTU e 12,8 NTU, no ponto P1 e P2, respectivamente, logo pode-se constatar que todos os dados estão em conformidade com a resolução e que os altos teores de TB no período chuvoso, podem ser associadas à alta correnteza, promovendo a dissolução e transporte de partículas, além da influência de atuação antrópica no curso d'água. A atuação da vazão sobre o parâmetro turbidez também foi verificado por Vasco et al. (2011) no Rio Poxim, em Sergipe.

Com relação ao OD, verifica-se que todos os valores estão em conformidade com a resolução, porém as coletas no mês de agosto apresentaram as menores concentrações do período seco no ponto P1 $(6,1 \mathrm{mg} / \mathrm{L})$ e P2 $(6,6 \mathrm{mg} / \mathrm{L})$ o que pode indicar a poluição das águas por despejos orgânicos.

O cenário de contaminação constatado no mês de agosto pode ser comprovado com os maiores graus de eutrofização identificados no período seco, assim como devido i) às concentrações máximas de PT durante toda a campanha de amostragem $(0,1946$ e $0,30246 \mathrm{mg} / \mathrm{L})$, ii) o valor de DBO no ponto P1 (5,6 mg/L) em desconformidade com a legislação e iii) em decorrência da elevada detecção de CT em P1 (241960 NMP/100 mL).

A variável $\mathrm{Cl}$ está associado à contaminação por fontes receptoras de esgoto doméstico ou associadas a aterros sanitários e lixões (Lima et al., 2013). Verifica-se que ainda que todos os dados estão abaixo do limite estabelecido pela legislação $(\mathrm{Cl}<250 \mathrm{mg} / \mathrm{L})$, e os máximos teores desse parâmetro também foram identificados no mês de agosto, no qual observou-se a concentração de 17,0 e 9,0 $\mathrm{mg} / \mathrm{L}$ em P1 e P2, respectivamente.

Ao analisar as médias da variável $\mathrm{Cl}$, constata-se médias superiores em P1 que variaram de 6,1 a $8,9 \mathrm{mg} / \mathrm{L}$, desta forma, pode se constatar que o ponto P1 recebe maior carga de efluentes conforme constatado na pesquisa realizada por Vasconcelos et al. (2002) referente aos parâmetros coliformes totais e fecais.

A variável $\mathrm{CE}$ relaciona-se à concentração iônica da água como partículas carregadas eletricamente (Libânio, 2010). A média no ponto P1 variou de 157,5 a $160,3 \mu \mathrm{S} / \mathrm{cm}$, no qual foi superior ao ponto P2 com média entre 121,7 e $130 \mu \mathrm{S} / \mathrm{cm}$. Constata-se assim que a concentração em P1 pode estar relacionada à alta correnteza do curso 
d'água que promove a diluição dos íons segundo Esteves (2011).

0 parâmetro SST apresentou valores superiores no ponto P1, comprovando sua correlação com a variável CE. Verifica-se que os pontos $\mathrm{P} 1 \mathrm{e}$ P2 apresentaram no período chuvoso valores acima do limite estabelecido na resolução com a mesma representatividade de $33,33 \%$.
A variável $\mathrm{NO}_{3}$ consiste no último estado do processo de nitrificação do nitrogênio, desta forma, indica uma poluição antiga, enquanto que o nitrogênio amoniacal pode ser relacionado ao lançamento de despejos domésticos recentes (Vasco et al., 2011). Verifica-se que foi detectado concentração de nitrato apenas no ponto P1 com valores abaixo do limite estabelecido na legislação.

Tabela 5. Parâmetros físicos, químicos e biológicos nos pontos amostrais (P1 e P2), bem como os valores máximos estabelecidos na Resolução do CONAMA no 357 (Brasil, 2005).

\begin{tabular}{|c|c|c|c|c|c|c|c|c|c|c|c|c|c|c|}
\hline Data & $\mathbf{T}_{\mathrm{H} 20}$ & pH & CA & TB & OD & $\mathrm{CE}$ & $\mathbf{A}$ & $\mathbf{C l}$ & D & SDT & $\mathrm{NO}_{3}$ & DBO & CT & EC \\
\hline \multicolumn{15}{|c|}{ P1 - Estação seca } \\
\hline jun/2018 & 21,4 & 7,7 & 57,7 & 10,1 & 8,3 & 134,2 & 12,3 & 4,0 & 22,0 & ND & ND & ND & ND & ND \\
\hline jul/2018 & 18,9 & 7,6 & 52,3 & 8,8 & 7,7 & 132,3 & 9,0 & 2,3 & 22,7 & ND & 0,10 & ND & 12033 & 160 \\
\hline ago/2018 & 21,4 & 7,3 & 66,3 & 11,2 & 6,1 & 164,0 & 10,1 & 17,0 & 28,0 & 202,0 & 0,45 & 5,6 & 241960 & 158 \\
\hline set/2018 & 21,6 & 7,4 & 36,9 & 5,7 & 6,9 & 210,5 & 11,1 & 12,3 & 41,3 & 88,0 & 0,54 & 2,4 & 6131 & 75 \\
\hline Média & 20,8 & 7,5 & 53,3 & 8,9 & 7,2 & 160,3 & 10,6 & 8,9 & 28,5 & 145,0 & 0,36 & 4,0 & 86708 & 131 \\
\hline$\sigma$ & 1,3 & 0,2 & 12,4 & 2,4 & 1,0 & 36,5 & 1,4 & 6,9 & 9,0 & 80,6 & 0,23 & 2,3 & 134485 & 49 \\
\hline CV (\%) & 6,2 & 2,7 & 23,2 & 26,8 & 13,4 & 22,8 & 13,1 & 77,8 & 31,5 & 55,6 & 63,80 & 56,6 & 155 & 37 \\
\hline \multicolumn{15}{|c|}{ P1 - Estação chuvosa } \\
\hline out/2018 & 27,5 & 7,4 & 55,7 & 7,4 & 5,4 & 188,6 & 12,9 & 8,0 & 29,3 & 142,0 & 0,49 & 4,7 & 19863 & 185 \\
\hline nov/2018 & 23,9 & 7,4 & 159,0 & 41,8 & 7,3 & 138,3 & 13,1 & 5,7 & 36,7 & 140,0 & ND & 4,1 & 32550 & 410 \\
\hline $\operatorname{dez} / 2018$ & 25,1 & 7,3 & 163,0 & 38,2 & 7,8 & 145,6 & 10,1 & 4,7 & 35,0 & 1776,0 & 0,52 & 3,3 & 41060 & 410 \\
\hline Média & 25,5 & 7,4 & 125,9 & 29,1 & 6,8 & 157,5 & 12,0 & 6,1 & 33,7 & 686,0 & 0,51 & 4,0 & 31158 & 335 \\
\hline $\boldsymbol{\sigma}$ & 1,8 & 0,1 & 60,8 & 18,9 & 1,2 & 27,2 & 1,7 & 1,7 & 3,8 & 944,0 & 0,02 & 0,7 & 10667 & 130 \\
\hline CV (\%) & 7,2 & 0,7 & 48,3 & 65,0 & 18,2 & 17,3 & 13,8 & 28,0 & 11,4 & 137,6 & 4,18 & 17,4 & 34 & 39 \\
\hline \multicolumn{15}{|c|}{ P2 - Estação seca } \\
\hline jun/2018 & 24,5 & 7,6 & 31,0 & 11,3 & 7,7 & 121,8 & 13,9 & 4,3 & 26,7 & ND & ND & ND & ND & ND \\
\hline jul/2018 & 21,5 & 7,5 & 52,5 & 12,7 & 6,9 & 116,3 & 9,8 & 1,7 & 24,7 & ND & ND & ND & 19863 & 1246 \\
\hline ago/2018 & 21,7 & 7,5 & 46,1 & 10,0 & 6,6 & 121,1 & 10,3 & 9,0 & 27,3 & 86,0 & ND & 3,5 & ND & ND \\
\hline set/2018 & 22,3 & 7,4 & 22,2 & 6,0 & 6,9 & 127,7 & 6,8 & 3,3 & 26,0 & 145,0 & ND & 3,3 & 27550 & 1480 \\
\hline Média & 22,5 & 7,5 & 38,0 & 10,0 & 7,0 & 121,7 & 10,2 & 4,6 & 26,2 & 115,5 & ND & 3,4 & 23707 & 1363 \\
\hline $\boldsymbol{\sigma}$ & 1,4 & 0,1 & 13,8 & 2,9 & 0,4 & 4,7 & 2,9 & 3,1 & 1,1 & 41,7 & ND & 0,1 & 5436 & 165 \\
\hline CV (\%) & 6,1 & 1,3 & 36,5 & 28,8 & 6,4 & 3,8 & 28,8 & 68,7 & 4,3 & 36,1 & ND & 4,2 & 23 & 12 \\
\hline \multicolumn{15}{|c|}{ P2 - Estação chuvosa } \\
\hline out/2018 & 25,4 & 7,4 & 25,4 & 6,7 & 6,1 & 129,2 & 10,1 & 2,0 & 26,7 & 768,0 & ND & 4,9 & 81640 & 3130 \\
\hline nov/2018 & 24,7 & 7,3 & 46,3 & 15,4 & 7,1 & 132,9 & 12,5 & 4,0 & 40,0 & 100,0 & ND & 3,6 & 64880 & 1890 \\
\hline $\operatorname{dez} / 2018$ & 25,4 & 7,6 & 56,2 & 16,4 & 6,9 & 127,8 & 10,4 & 2,5 & 39,0 & 50,0 & ND & 3,7 & ND & ND \\
\hline Média & 25,2 & 7,5 & 42,6 & 12,8 & 6,7 & 130,0 & 11,0 & 2,8 & 35,2 & 306,0 & ND & 4,1 & 73260 & 2510 \\
\hline$\sigma$ & 0,4 & 0,2 & 15,7 & 5,4 & 0,5 & 2,6 & 1,3 & 1,0 & 7,4 & 400,9 & ND & 0,7 & 11851 & 877 \\
\hline CV (\%) & 1,6 & 2,2 & 36,9 & 41,7 & 8,0 & 2,0 & 11,9 & 36,7 & 21,1 & 131,0 & ND & 17,8 & 16 & 35 \\
\hline
\end{tabular}




\begin{tabular}{|c|c|c|c|c|c|c|c|c|c|c|c|c|c|c|}
\hline & & & & & & & & & & & & & & \\
\hline RC357 & - & $\begin{array}{c}6,0 \\
- \\
9,0\end{array}$ & $<75$ & $<100$ & $>5$ & - & - & $<250$ & - & $<500$ & $<10$ & $<5$ & - & $<1000$ \\
\hline
\end{tabular}

$\mathrm{T}_{\mathrm{H} 20}$ - Temperatura da água $\left({ }^{\circ} \mathrm{C}\right) ; \mathrm{CA}$ - Cor Aparente (mg.Pt/L); TB - Turbidez (NTU); OD - Oxigênio Dissolvido (mg/L); CE - Condutividade Elétrica $\left(\mu \mathrm{S} . \mathrm{cm}^{-1}\right) ; \mathrm{A}$ - Alcalinidade $(\mathrm{mg} / \mathrm{L} \mathrm{CaCO} 3) ; \mathrm{Cl}$ Cloreto (mg/L); D - Dureza (mg/L); SDT - Sólidos Dissolvidos Totais (mg/L); $\mathrm{NO}_{3}$ - Nitrato (mg/L $\mathrm{N}$ ); CT - Coliformes Termotolerantes (NMP/100 mL); EC - Escherichia coli (NMP/100 mL); Sublinhado - concentração acima do limite estabelecido na Resolução CONAMA no 357/2005 (BRASIL, 2005). RC357 - Resolução CONAMA no 357/2005. 
A variável EC, segundo Libânio (2010), pode ser relacionada à contaminação fecal de animais de sangue quente. Sendo assim, verifica-se que $50 \%(2 / 4)$ das amostras no período chuvoso e $66,67 \%$ no período seco pertencente ao ponto P2 estão acima do limite estabelecido na Resolução CONAMA no $357 / 2005$ (Brasil, 2005) de 1.000 NMP/100 mL para os usos múltiplos, exceto recreação de contato primário.

\section{Conclusões}

0 presente trabalho permitiu concluir que o $\mathrm{IET}_{2}$ de Lamparelli (2004) apresentou maior confiabilidade para a avaliação do grau de trofia dos mananciais de abastecimento do município de Goiânia.

Com relação ao $\mathrm{IET}_{2}$, verifica-se que houve diferenças significativas entre as estações do ano $(p=0,016)$, com agravamento da qualidade da água na estação seca. Logo, conclui-se que os pontos P1 e P2 foram classificados no período seco como mesotrófico e no período chuvoso o ponto P2 foi classificado como ultraoligotrófico.

De acordo com os resultados das análises laboratoriais, pode-se concluir que os parâmetros fósforo total, cor aparente, sólidos dissolvidos totais, DBO e Escherichia Coli apresentaram valores superiores aos limites estabelecidos na Resolução do CONAMA no 357 (Brasil, 2005) para águas destinadas ao abastecimento humano, após o tratamento convencional.

Constata-se também que a coleta do mês de agosto apresentou comprometimento acentuado da qualidade da água nos pontos P1 e P2. Tal situação pode ser relacionada ao lançamento de efluentes orgânicos em decorrência dos valores máximos de fósforo total, cloreto e coliformes totais identificados nessa campanha, além do valor de DBO em desconformidade com a legislação.
Logo, com a finalidade de promover uma melhoria da qualidade e redução da degradação desses cursos d'água, deve-se realizar o monitoramento contínuo da qualidade da água e a implantação de medidas de recuperação e prevenção que envolvem os usos do solo na bacia.

\section{Conflito de interesses}

As autoras declaram não haver conflito de interesses.

\section{Referências}

Alves, I. C.; El-Robrini, M.; Santos, M. D. L. S.; Moura Monteiro, S.; Barbosa, L.P.F.; Guimarães, J.T.F. Qualidade das águas superficiais e avaliação do estado trófico do Rio Arari (Ilha de Marajó, Norte do Brasil). Acta Amazonica, v. 42, n. 1, p. 115-124, 2011. https://doi.org/10.1590/S0044-59672012 000100014

APHA - American Public Health Association. Standard methods for the examination of water and wastewater. 22. ed. Washington: American Water Association, Water Environmental Federation, 2012.

Brasil. Resolução CONAMA no 357, de 7 de março de 2005. Dispõe sobre a classificação dos corpos de água e diretrizes ambientais para o seu enquadramento, bem como estabelece as condições e padrões de lançamento de efluentes e dá outras providências. Disponível em: <http://www2.mma.gov.br/port/conam a/legiabre.cfm?codlegi $=459>$. Acesso em: 25 abr. 2019.

Carlson, R. E. A trophic state index for lakes. Limnology and Oceanography, v. 22, n. 2, p. 261-269, 1977. https://doi.org/10.4319/ lo.1977.22.2.0361

CETESB - Companhia Ambiental do Estado de São Paulo. Guia nacional de coleta e preservação de amostras: água, sedimento, comunidades aquáticas e efluentes líquidos. São Paulo: CETESB, 2011.

CETESB - Companhia Ambiental do Estado de São Paulo. Índices de qualidade das águas. São Paulo: CETESB, 2017. 
Cunha, D.; Borges, E. Urbanização acelerada: risco para o abastecimento de água na Região Metropolitana de Goiânia. Geo UERJ, n. 26, p. 226-244, 2015. https://doi.org/10.12957/ geouerj.2015.13816

Esteves, F. D. A. Fundamentos de Limnologia. 3. ed. Rio de Janeiro: Interciência, 2011.

Farage, J. A. P.; Matos, A. T.; Silva, D. D.; Borges, A. C. Determinação do índice de estado trófico para fósforo em pontos do Rio Pomba. Engenharia na Agricultura, v. 18, n. 4, p. 322329, 2010. https://doi.org/10.13083/reveng. v18i4.98

Fia, R.; Matos, A.; Coradi, P.; Ramirez, O. Estado trófico da água na bacia hidrográfica da Lagoa Mirim, RS, Brasil. Revista Ambiente \& Água, v. 4 , p. 132-141, 2009. https://doi.org/ 10.4136/ambi-agua.78

IMASUL - Instituto de Meio Ambiente do Mato Grosso do Sul. Significado da cor para o tratamento sanitário da água. Disponível em: <http://www.licenciamentoambiental.eng.br/ significado-sanitario-da-cor-para-o-

tratamento-de-agua/>. Acesso em: 8 jun. 2019.

INMET - Instituto Nacional de Meteorologia. Estações Convencionais: Gráficos. 2019. Disponível em: <http://www.inmet.gov.br/ portal/index.php?r=home/page\&page=rede_e stacoes_conv_graf>. Acesso em: 7 jan. 2019.

Köppen, W. Climatologia: com um estudio de los climas de la tierra. Mexico: Fondo de Cultura Economica, 1948.

Lamparelli, M. C. Grau de trofia em corpos d'água do estado de São Paulo: avaliação dos métodos de monitoramento. São Paulo: Universidade de São Paulo, 2004. (Tese de doutorado).

Libânio, M. Fundamentos de qualidade e tratamento de água. 3. ed. Campinas: Átomo, 2010.

Lima, J.; França, A.; Loiola, H. Implicações hidroquímicas da condutividade elétrica e do íon cloreto na qualidade das águas subterrâneas do semiárido cearense. Revista Virtual de Química, v. 6, n. 2, p. 279-292, 2013. https://doi.org/10.5935/1984-6835. 20140020

Lobato, E. J. V. Estação evaporimétrica de Goiânia: normais climatológicas (1975-2004). Goiânia: EAEA, 2005.
López-Monroy, F.; Troccoli-Ghinaglia L. Aplicación de índices de estado trófico en la laguna costera tropical las Marites (Isla de Margarita, Venezuela). Saber, v. 18, n. 30, p. 151-159, 2018.

Mendes, T. A.; Fagundes, A. K. B.; Pereira, T. S. R. Classificação preliminar de corpos d'água com base na Resolução CONAMA no 357/2005: caso do Rio Meia Ponte-GO. Ciência e Natura, v. 38, n. 3, p. 1382-1393, 2016. https://doi.org/10.5902/2179460X21832

Monteiro, T. R.; Oliveira, L. G.; Godoy, B. S. Biomonitoramento da qualidade de água utilizando macroinvertebrados bentônicos: adaptação do índice biótico BMWP à Bacia do Rio Meia Ponte-GO. Oecologia Brasiliensis, v. 12 , n. 3 , p. $553-563,2008$.

Santos, E.; Griebeler, N.; Oliveira, L. Relação entre uso do solo e comportamento hidrológico na Bacia Hidrográfica do Ribeirão João Leite. Revista Brasileira de Engenharia Agrícola e Ambiental, v. 14, n. 8, p. 826-834, 2010. https://doi.org/10.1590/S1415-436620 10000800006

Silva, G. S. D.; Miola, S.; Silva, G. S. D.; Sousa, E. R. D. Avaliação da qualidade das águas do Rio São Francisco Falso, tributário do Reservatório de Itaipu, Paraná. Eclética Química, v. 35, n. 3, p. 117-122, 2010. https://doi.org/10.1590/ S0100-46702010000300011

Sinha, E; Michalak, A; Balaji, V. Eutrophication will increase during the 21st century as a result of precipitation changes. Science, v. 357, n. 6349 , p. 405-408, 2017. https://doi.org/ 10.1126/science.aan2409

Toledo Jr., A. P. Informe preliminar sobre os estudos para obtenção de um índice para avaliação do estado trófico de reservatórios de regiões quentes tropicais. São Paulo: CETESB, 1990. (Relatório Interno CETESB).

Toledo Jr., A. P.; Talarico, M.; Chinez, S. J.; Agudo, E.G.A aplicação de modelos simplificados para a avaliação do processo de eutrofização em lagos e reservatórios tropicais. Anais do XIX Congresso Interamericano de Engenharia Sanitária e Ambiental, AIDIS, Santiago, p. 56, 1984.

Toledo Jr., A. P.; Talarico, M.; Chinez, S. J.; Agudo, E. G. A aplicação de modelos simplificados para a avaliação do processo de eutrofização em lagos e reservatórios tropicais. Anais do II Congresso Brasileiro de 
Engenharia Sanitária e Ambiental, Camburiú, p. 34, 1983.

Vasco, A. N.; Britto, F. B.; Pereira, A. P. S.; Méllo Júnior, A. V. M.; Garcia, C. A. B.; Nogueira, L. C. Avaliação espacial e temporal da qualidade da água na bacia do Rio Poxim, Sergipe, Brasil. Revista Ambiente \& Água, v. 6, n. 1, p. 118130, 2011.

Vasconcelos, S.; Serafini, A.; Marques, R. Ocorrência de indicadores de poluição nos mananciais de abastecimento da Cidade de Goiânia, Goiás-Brasil: coliformes totais e fecais. Anais do XXVIII Congreso Interamericano de Ingeniería Sanitaria y Ambiental, FEMISCA, p. 1-4, 2002.

Informação da Licença: Este é um artigo Open Access distribuído sob os termos da Licença Creative Commons Attribution, que permite uso irrestrito, distribuição e reprodução em qualquer meio, desde que a obra original seja devidamente citada. 